\section{P-32 SUPPORTIVE CARE OF ORAL MUCOSITIS IN HAEMATOLOGY PATIENTS: SERVICE EVALUATION AND IMPROVEMENT PROJECT}

${ }^{1}$ Claire Nicola MacDermott, 'James Davies, 'Cannon Thomas, 1,25am Fingas. 'Sheffield Teaching Hospitals NHS Foundation Trust, Sheffield, UK; ${ }^{2}$ St Luke's Hospice, Sheffield, UK

\subsection{6/bmjspcare-2017-00133.32}

In haematological malignancy high dose chemotherapy or bone marrow transplant commonly cause oropharyngeal mucositis. At Sheffield Teaching Hospitals NHS Foundation Trust $(\mathrm{STH})$ there is joint working between palliative care (PCT) and haematology to manage these patients. The aim was to evaluate the service, implement improvements and re-evaluate.

Initial evaluation was performed against the STH Standard Operating Procedures (SOP) for haematology patients suffering with mucositis and referred to PCT. Convenience sampling was used and data collected between April-October 2015. Case notes of 19 patients referred to PCT with mucositis were reviewed. The SOP recommends referral to PCT if third line interventions fail. The results of the initial evaluation showed that most patients, 18 and 17 patients respectively, had antacid-oxceitacaine and lidocaine mouthwashes prescribed. Only $1(5 \%)$ had the treatment fully optimised; i.e. alternating four hourly and to swallow. Fifteen patients (79\%) were referred to PCT before completing third line treatment without systemic treatment with opioid being initiated.

Intervention An education programme and simple flowchart for prescribing was developed with a new SOP.

Final evaluation was performed on the next 11 sequential haematology patients with mucositis from February-April 2016. All patients had the mouthwashes prescribed with appropriate frequency and route. Six patients required systemic PRN or regular opioids. Four patients (67\%) had PRN opioids prescribed appropriately. All transdermal patches (buprenorphine or fentanyl) were prescribed and titrated appropriately. One patient (9\%) was referred to PCT team earlier than the flowchart recommended compared to $79 \%$ previously. A survey of staff reported increased confidence with prescribing and improvement in patient experience, with PCT only reviewing those with specialist needs.

Conclusion This service evaluation and improvement project has enhanced prescribing and the confidence of haematology team in managing those with mucositis.

\section{P-33 A SURVEY OF JUNIOR DOCTORS' CONFIDENCE IN PROVIDING END OF LIFE CARE}

Sonya Hessey, Suraj Shah, Sangita Chatterjee, Jo Wilson, Louise Schofield. Royal Free NHS Foundation Trust, London, UK

\subsection{6/bmjspcare-2017-00133.33}

Background Palliative care is increasingly incorporated into undergraduate curriculums in UK medical schools. Training needs of junior doctors who frequently provide care for dying patients, however, are less well elucidated.

Aim We set out to assess junior doctors' confidence in various areas of End of Life Care in order to identify specific training needs.

Method We adapted the University College London Hospital Care of the Dying Confidence Questionnaire to focus on areas of End of Life Care relevant to junior doctors. We distributed a paper and online version of this questionnaire to trainees in acute, surgical and medical specialties at the Royal Free NHS Foundation Trust. The statistical significance of the difference between Likert scale medians was determined by KruskalWallis tests.

Results We received 95 survey responses from doctors in foundation $(71 \%)$, core $(19 \%)$ and specialty registrar (10\%) training years. Unsurprisingly, higher training grade was associated with increased confidence in providing End of Life Care, in particular in discussing dying and ceiling of care with patients and their family members. All trainees were confident (Likert median=6) in verifying death and writing death certificates. Trainees reported low confidence (Likert median=4) in discussing the discontinuation of nutrition and hydration as well as in caring for a dying patient who becomes unconscious.

Conclusion Junior doctors are confident in skills routinely taught and tested during medical school. There remains a need for additional End of Life Care training, in particular for foundation trainees. To optimise the End of Life Care provided by junior doctors this training should focus on areas of low confidence such as discussing nutrition and hydration.

\section{P-34 THE PERSONAL, PROFESSIONAL AND INSTITUTIONAL IMPACT OF BEING A MENTOR TO A PALLIATIVE CARE TEAM IN A LOW-INCOME COUNTRY}

'Jane Whitehurst, ${ }^{2}$ Julie Rowlands. 'Guy's and St Thomas' NHS Foundation Trust, London, UK: ${ }^{2}$ Aneurin Bevan Local Health Board

10.1136/bmjspcare-2017-00133.34

Background Global access to palliative care is improving but inadequate. In 2011, only $58 \%$ of countries had one or more palliative care service. Palliative care expertise and successful service models exist in low-income countries but the scale of demand indicates a role for additional international support to aid service expansion and training. Global health partnerships aim for mutual benefits; research shows that international health volunteering benefits volunteers and employers by developing professional and leadership skills. Health-related mentorship research in higher-income countries recognises wide-ranging benefits to mentors themselves. Less is known regarding the professional and institutional impacts of shortterm international mentoring or if being a mentor in a lowincome country offers transferable benefits for UK palliative care.

Aim To ascertain the personal and professional impact of being a mentor to a palliative care team based in a lowincome country and identify transferable benefits for UK healthcare institutions.

Method UK-employed, palliative care clinicians: four consultants, two specialty trainees, and a nurse, were recruited from an international palliative care initiative incorporating mentorship. Semi-structured telephone interviews were recorded and analysed using interpretive phenomenological analysis.

Results All mentors described positive personal, professional and institutional impacts of international mentorship, whilst acknowledging the need to address challenges and complex emotions. Personal impact stemmed from exploring one's own value: fulfilling a humanitarian drive, working through challenges and rationalising lived experiences. Professional impacts resulted from experiential learning regarding management, leadership and mentoring; stimulating reflection on own UK 